\title{
SERUM CHOLESTEROL AND TRIGLYCERIDES IN PARKINSON'S DISEASE AND ESSENTIAL TREMOR
}

\author{
Borislav Ivanov ${ }^{1}$, Ara Kaprelyan ${ }^{2}$, Ivan Dimitrov, ${ }^{3}$ Margarita Grudkova ${ }^{2}$, Natalia Usheva ${ }^{4}$, Vesselina \\ Nestorova ${ }^{5}$, and Nadezhda Deleva ${ }^{2}$ \\ ${ }^{1}$ Department of Clinical Medical Sciences, Medical University and First Clinic of Neurology, \\ University St Marina Hospital, Varna, Bulgaria, ${ }^{2}$ Departmentof Neurology, Medical University, Varna, \\ Bulgaria, ${ }^{3}$ Department of Nursing, Sliven Affiliate, Medical University, Varna, Bulgaria, ${ }^{4}$ Department \\ of Social Medicine and Healthcare Organization, Medical University, Varna, Bulgaria, ${ }^{5}$ Department of \\ Physiotherapy, Rehabilitation, Thalassotherapy, Occupational Diseases and Disaster Medicine, \\ Medical University, Varna, Bulgaria
}

The role of lipid metabolism in the pathogenesis of Parkinson`s disease is still controversial. Most authors suggest that higher The role of lipid metabolism in the pathogenesis of Parkinson 's disease is still controversial. Most authors suggest that higher serum cholesterol may be associated with a lower risk of Parkinson's disease. Debates exist as to whether essential tremor shares similar neuropathological mechanisms as Parkinson`s disease. We investigated serum total cholesterol and triglyceride levels in a clinical setting of Parkinson's disease versus essential tremor patients. Two hundred and sixteen Parkinson's disease patients (126 males), aged 68.04 years, with 4.58 years disease duration and 342 essential tremor patients (118 males), aged 69.39 years, with 5.3 years disease duration were included, hospitalized during a period of 7 years in First Clinic of Neurology, University St Marina Hospital, Varna, Bulgaria. We found insignificantly higher levels of serum total cholesterol and triglyceride in essential tremor patients. Results differ statistically only on gender level with increased cholesterol in males and triglycerides in females. Our findings may indicate divergent pathophysiological mechanisms underlying Parkinson`s disease and essential tremor. Further research may elucidate the role of lipid metabolism changes in both diseases.

Biomed Rev 2015; 26: 43-46.

Key words: serum total cholesterol, triglycerides, Parkinson`s disease, essential tremor

Received 1 December 2015, revised 10 December 2015, accepted 18 December 2015.

Correspondence to Dr Borislav Ivanov, MD, PhD, Department of Clinical Medical Sciences, Medical University and First Clinic of Neurology, University St Marina Hospital, Varna, Bulgaria. Tel.: 35952 978524; E-mail: borislav.ivanov@mail.bg 


\section{INTRODUCTION}

There are growing evidences that changes of lipid metabolism are involved in the pathophysiology of neurodegenerative diseases $(1,2)$ Several large prospective and populationbased studies have reported controversial results. Most authors suggest that higher serum cholesterol may be associated with lower risk of Parkinson`s disease (PD) (3). Meanwhile, it was shown that PD patients have lower cholesterol than controls (4). Debates exist as to whether essential tremor (ET) shares similar pathophysiological mechanisms with PD (5).

\section{SUBJECTS AND METHODS}

We investigated serum total cholesterol and triglycerides levels in a clinical setting of 216 PD patients (126 males, 90 females), aged $68.0 \pm 9.3$ years (40-85 years), with 4.6 \pm 3.9 years (1-20 years) disease duration, and 342 ET patients (118 males, 224 females), aged 69.4 \pm 8.3 years (32-91 years), with $5.3 \pm 6.2$ years ( $1-40$ years) disease duration, as hospitalized in a 7-year period at First Clinic of Neurology, University St Marina Hospital Varna, Bulgaria.

\section{RESULTS}

For the Parkinson's disease group levels of serum total cholesterol and triglycerides were as follow: $5.06 \pm 1.17 \mathrm{mmol} / 1$ (2.5-8.94) and $1.29 \pm 0.64 \mathrm{mmol} / \mathrm{l}(0.41-3.9)$ versus $5.33 \pm$ $1.14 \mathrm{mmol} / \mathrm{l}(2.17-9.8)$ and $1.53 \pm 0.77 \mathrm{mmol} / \mathrm{l}(0.31-5.51)$ respectively for essential tremor patients. The laboratory's referent level for serum total cholesterol was $\leq 5.2 \mathrm{mmol} / \mathrm{l}$, and for triglycerides was $\leq 2.83 \mathrm{mmol} / \mathrm{l}$. Age and disease duration of $\mathrm{PD}$ and $\mathrm{ET}$ groups did not differ significantly. The values of serum total cholesterol and triglycerides in PD and ET groups are shown of Table 1.

Differences reach statistical significance only for males for serum total cholesterol and females for triglycerides (Table 2) with higher levels in the ET group.

Mean levels of serum total cholesterol for ET is higher than the laboratory norm (2.7-5.2 $\mathrm{mmol} / \mathrm{l})$, whereas serum total cholesterol levels for PD and triglycerides levels for both $\mathrm{PD}$ and $\mathrm{ET}(\leq 2.83 \mathrm{mmol} / \mathrm{l})$ are within the normal range (Table 3).

Table 1.Values of serum total cholesterol (STCh) and triglycerides (3-gly) in Parkinson's disease (PD) and essential tremor (ET) patients

\begin{tabular}{|c|c|c|}
\hline & Serum total cholesterol & Triglyceride \\
\hline $\mathrm{PD}$ & $5.06 \pm 1.17 \mathrm{mmol} / \mathrm{I}(2.5-8.9)$ & $1.29 \pm 0.64 \mathrm{mmol} / \mathrm{l}(0.4-3.9)$ \\
\hline $\mathrm{ET}$ & $5.33 \pm 1.14 \mathrm{mmol} / \mathrm{I}(2.2-9.8)$ & $1.53 \pm 0.77 \mathrm{mmol} / \mathrm{l}(0.3-5.5)$ \\
\hline
\end{tabular}

Table 2. Values of serum total cholesterol (STCh) and triglycerides (3-gly) according to gender (mmol/l)

\begin{tabular}{|c|c|c|c|c|}
\hline & STCh Males & STCh Females & 3-gly Males & 3- gly Females \\
\hline PD & $\begin{array}{c}4.78 \pm 1.11^{*} \\
(2.5-8.94)\end{array}$ & $\begin{array}{c}5.47 \pm 1.14 \\
(3.07-8,85)\end{array}$ & $\begin{array}{l}1.32 \pm 0.69 \\
(0.41-3.9)\end{array}$ & $\begin{array}{c}1.25 \pm 0.57^{* *} \\
(0.45-2.85)\end{array}$ \\
\hline ET & $\begin{array}{l}5.17 \pm 1.12^{*} \\
(2,17-7,98)\end{array}$ & $\begin{array}{l}5.42 \pm 1.15 \\
(3,25-9,8)\end{array}$ & $\begin{array}{l}1.53 \pm 0.83 \\
(0,31-5,51)\end{array}$ & $\begin{array}{c}1.54 \pm 0.75^{* *} \\
(0,43-4,77)\end{array}$ \\
\hline
\end{tabular}

${ }^{*} \mathrm{p}=0.006$ (Independent samples t- test)

${ }^{* *} \mathrm{p}=0.001$ (Independent samples t- test)

Table 3. Distribution of patients, according to serum total cholesterol (STCh) and triglycerides (3-gly) values

\begin{tabular}{|c|c|c|c|c|c|}
\hline & Normal STCh and 3-gly & Low STCh & High STCh & High 3-gly & High STCh and 3-gly \\
\hline PD & $57.41 \%(n=124)$ & $0.46 \%(n=1)$ & $\begin{array}{c}38.89 \% \\
(n=84)\end{array}$ & $0.93 \%(n=2)$ & $\begin{array}{c}2.31 \% \\
(n=5)\end{array}$ \\
\hline ET & $46.49 \%(n=159)$ & $0.59 \%(n=2)$ & $47.95 \%(n=164)$ & $1.17 \%(n=4)$ & $\begin{array}{c}3.80 \% \\
(n=13)\end{array}$ \\
\hline
\end{tabular}




\section{DISCUSSION}

Essential tremor is the most common movement disorder. The possible relationship between ET and PD has been debated since the first description of PD by James Parkinson in 1817. There is increasing evidences suggesting an overlap between these two disorders (5). Cholesterol is vital for the neuronal functional and structural integrity. Brain cholesterol metabolism changes are linked to neurodegeneration (6). Data for lipids in ET are scarce. One study found increased levels of cholesterol in ET (7). Meanwhile several studies in PD obtained controversial results. Some authors suggest that higher serum total cholesterol may be associated with lower future risk of PD and slower disease progression, especially in females $(8-10,11)$, others found no association (12, 13 ), and one large study suggested that elevated serum total cholesterol is linked to elevated PD risk in males under 55 years of age (14). Most researchers agreed that serum total cholesterol and LDL in PD are lower as compared to controls (15). Recent Finnish study concluded that elevated serum triglycerides predicted low PD incidence (16).

We found insignificantly higher levels of serum total cholesterol and triglycerides in our ET patients. Results differ statistically only on gender levels. Gender differences are debated regarding the role of sex hormones and lipid metabolism (12). In regard to laboratory referent level, mean serum total cholesterol of ET patients is higher, supporting the results of (7). In vitro results suggested an association between cholesterol and localization and structure of alpha- synuclein, the essential protein component of Lewy bodies, pathological hallmark of PD. At the same time Lewy bodies were found in brainstems of $1 / 3$ of autopsied ET cases. Moreover, cholesterol is the most important determinant of levels of coenzyme Q10, a powerful antioxidant and mitochondrial electron acceptor, involved in pathophysiology of neurodegenerative diseases $(17,18)$.

Essential tremor is no more considered benign, monosymptomatic disorder. Growing evidences in the last 10 years suggested that ET is rather a neurodegenerative disease. Researching its comorbidity may extend the knowledge of underlying pathophysiological mechanisms.

\section{CONCLUSION}

Our findings of elevated serum total cholesterol and triglycerides in the ET group may be discussed as a potential indicator for divergent pathophysiological mechanisms underlying PD and ET. Further research may elucidate the role of lipid metabolism in both diseases.
Conflict of interest: the authors declare no conflict of interest.

\section{REFERENCES}

1. Liu J, Tang Y, Zhou S, Toh B, McLean C, Li H. Cholesterol involvement in the pathogenesis of neurodegenerative diseases. Mol Cell Neurosci 2010; 43, 1: 33-42. DOI: 10.1016/j.mcn.2009.07.013

2. Ritz B, Manthripragada A, Qian L, Schernhammer E, Wermuth L, Olsen J, et al. Statin use and Parkinson's disease in Denmark. Mov Disord 2010; 25, 9: 1210-1216. DOI: $10.1002 / \mathrm{mds} .23102$

3. Powers K, Smith-Weller T, Franklin G, Longstreth Jr W, Swanson P, Checkoway H. Dietary fats, cholesterol and iron as risk factors for Parkinson's Disease. Parkinsonism Relat Disord 2009; 15, 1: 47-52. DOI: 10.1016/j. parkreldis.2008.03.002

4. Roy A, Pahan K. Prospects of statins in Parkinson disease. Neuroscientist 2011; 17: 244-255. DOI: $10.1177 / 1073858410385006$.

5. Jimenez-Jimenez F, Alonso-Navarro H, Garcı-Martın E, Agundez J. The relationship between Parkinson's disease and essential tremor: Review of clinical, epidemiologic, genetic, neuroimaging and neuropathological data, and data on the presence of cardinal signs of parkinsonism in essential tremor. Tremor Other Hyperk Mov 2012; DOI: http://www.tremorjournal.org/index.php/tremor/ article/view/75

6. Zhang J, Liu Q. Cholesterol metabolism and homeostasis in the brain. Protein Cell. 2015; 6: 254-264. DOI: 10.1007/s13238-014-0131-3

7. Ivanova- Smolenskaia I, Korshunova T, Mzhelskaia T. Metabolic disorders in essential tremor. Zh Nevropatol Psikhiatr Im S S Korsakova 1980; 80, 12: 1765-1770.

8. Huang X, Abbott R, Petrovitch H, Mailman R, Ross G. Low LDL cholesterol and increased risk of Parkinson's disease: prospective results from Honolulu-Asia Aging study. Mov Disord 2008; 23, 7: 1013- 1018. DOI: 10.1002/mds.22013.

9. Huang X, Auinger P, Eberly S, Oakes D, Schwarzschild M, Ascherio A, et al. Parkinson Study Group DATATOP Investigators. Serum cholesterol and the progression of Parkinson's disease: results from DATATOP. PLoS One 2011; 6:e22854. DOI: 10.1371/ journal.pone.0022854 
10. Huang X, Chen H, Miller W, Mailman R, Woodard J, Chen $\mathrm{P}$, et al. Lower low density lipid cholesterol levels are associated with Parkinson's disease. Mov Disord 2007; 22: 377-381. DOI: 10.1002/mds. 21290

11. Miyake Y, Tanaka K, Fukushima W, Sasaki S, Kiyohara C, Tsuboi Y, et al. Parkinson's Disease Study Group. Case-control study of risk of Parkinson's disease in relation to hypertension, hypercholesterolemia, and diabetes in Japan. J Neurol Sci 2010; 293: 82- 86. DOI: 10.1016/j. jns.2010.03.002

12. Gudala K, Bansal D, Muthyala H. Role of serum cholesterol in Parkinson's disease: a meta-analysis of evidence. J Parkinsons Dis. 2013; 3, 3: 363-370. DOI: 10.3233/ JPD-130196.

13. Kelly S, Honglei C, Schwarzschild M, Ascherio A. Hypertension, hypercholesterolemia, diabetes, and risk of Parkinson disease. Neurology 2007; 69: 1688-1695. DOI: 10.1212/01.wnl.0000271883.45010.a8

14. Hu G, Antikainen R, Jousilahti P, Kivipelto M, Tuomileh- to J. Total cholesterol and the risk of Parkinson disease. Neurology 2008; 70, 21: 1972- 1979. DOI: 10.1212/01. wnl.0000312511.62699.a8

15. Undela K, Gudala K, Malla S, Bansal D. Statin use and risk of Parkinson's disease: a meta-analysis of observational studies. J Neurol 2013; 260, 1: 158- 165. DOI: 10.1007/s00415-012-6606-3

16. Sääksjärvi K, Knekt $P$, Männistö S, Lyytinen J, Heliövaara M. Prospective study on the components of metabolic syndrome and the incidence of Parkinson's disease. Parkinsonism Relat Disord 2015;21:1148-1155. DOI: 10.1016/j.parkreldis.2015.07.017.

17. de Lau L, Koudstaal P, Hofman A, Breteler M. Serum cholesterol levels and the risk of Parkinson's Disease. Am J Epidemiol 2006; 164: 998-1002. DOI: 10.1093/aje/ kwj283

18. Hu G. Total cholesterol and the risk of Parkinson's disease: A review for some new findings. Parkinsons Dis 2010; 2010:836962. DOI:10.4061/2010/836962 